Corresponding Author: Nazik Elmalaika Obaid Seid Ahmed Husain; email: nazikhusain@gmail.com

Received: 15 June 2017 Accepted: 1 July 2017 Published: 4 July 2017

Production and Hosting by Knowledge E

(c) Rufaida Mustafa Ahmed Mustafa and Nazik Elmalaika Obaid Seid Ahmed Husain. This article is distributed under the terms of the Creative Commons Attribution License, which permits unrestricted use and redistribution provided that the original author and source are credited.

Editor-in-Chief:

Prof. Mohammad A. M.

\section{Changes in Serum Iron, Total Iron Binding Capacity and Transferrin Saturation Percent in Sudanese Females Newly Diagnosed with Breast Cancer at Khartoum Oncology Hospital: A Case - Control Study}

\section{Rufaida Mustafa Ahmed Mustafa ${ }^{1}$ and Nazik Elmalaika Obaid Seid Ahmed Husain²}

${ }^{1}$ B.Sc, M.Sc, Hematology and Immunohematology, Sudan University of Science and Technology, Sudan

${ }^{2}$ MBBS, MSc, MD Clinical Pathology, Department of Pathology, Faculty of Medicine and Health Sciences, Omdurman Islamic University and Medical Laboratory Department, Khartoum Oncology Hospital, Sudan

\section{Abstract}

Background: Iron is a vital constituent of cells but in excess may be harmful and is associated with a raised risk for some malignant diseases including breast cancer. We aimed to study changes in iron profile in Sudanese females newly diagnosed with breast cancer. Methods: A case- control study in which serum iron, Total Iron Binding Capacity (TIBC), and transferrin saturation percent were measured for fifty females with breast cancer referred to Khartoum Oncology Hospital and seventy apparently healthy females, using manual method (IRON-FERROZINE). Results: Mean age was 47 years and 42 years in cases and control, respectively and the mean of parity was 4 in both groups. Mean of serum iron \pm SD in case group was $244.30 \pm 151.598(\mu \mathrm{g} / \mathrm{dL})$ and in control group was $57.59 \pm 43.191(\mu \mathrm{g} / \mathrm{dL})(\mathrm{P}$. value $=0.000)$. Mean of $\mathrm{TIBC} \pm \mathrm{SD}$ in cases was $412.98 \pm 177.460(\mu \mathrm{g} / \mathrm{dL})$ and in controls it was $403.71 \pm 168.765(\mu \mathrm{g} / \mathrm{dL})$ $(P$. value $=0.838)$. The mean of transferrin saturation percent \pm SD in cases was 61.08 $\% \pm 41.523$ and in controls was $223.23 \% \pm 149.195$ (P. value=0.000). The mean of TIBC in grade I $343.00(\mu \mathrm{g} / \mathrm{dL}), 467.10(\mu \mathrm{g} / \mathrm{dL})$ in grade II and $321.25(\mu \mathrm{g} / \mathrm{dL})$ in grade III (P. value 0.019) according to Modified Bloom Richardson's grading system. Conclusion: There is a statistically significant increase in the mean of serum iron and decrease in transferrin saturation percent in women with breast cancer. TIBC vary significantly according to histopathological grade. Serum iron and transferrin saturation percent may be helpful as biochemical risk markers for breast cancer and TIBC may act as a predictor of disease grade.

Keywords: Iron profile, serum iron, TIBC, Transferrin saturation percent, breast cancer, Modified Bloom Richardson's grading system, Sudan 


\section{Introduction}

Breast cancer is the most common malignancy in females worldwide with estimated incidence of 252.710 invasive breast cancer and 41.070 deaths expected in 2017 in the United States alone [1]. In Sudan, breast cancer incidence is increasing. Its frequency was 610 (10.01\% of registered cancer cases) in 2003 and 1015 (16.7\% of registered cancer cases) in 2010 as referred to Statistic Department at Khartoum Oncology Hospital. Moreover, breast cancer showed high incidence in young and middle age group ( $27 \%$ at $41-50$ years old and $26 \%$ at group $31-40$ years old) [2].

Iron is necessary for human life. Most functional iron is in the form of haemoglobin and myoglobin, but a small, significant portion of iron is used to bind with cofactors essential to basic metabolic oxidative and reduction reactions. The regulation of body iron is complex and exquisitely done so as to preserve iron needed but not to allow highly toxic excess [3].

Although iron is a crucial element for cells but in excess may be dangerous. Iron overload is linked with an elevated risk for some malignant diseases, including breast cancer [4]. Iron is necessary for cell proliferation and iron metabolism is influenced by oestrogen hormones. Interactions between iron and oestrogen may synergistically promote breast cancer [5].

Cancer patient suffers from many abnormalities. Females with breast cancer suffer from anaemia which is related directly to cancer, such those patients when given therapeutic iron to treat anaemia may impact with a prognosis of breast cancer.

A few published studies showed a relationship between serum iron, TIBC and transferrin saturation percent and breast cancer and they pointed to the need for more studies.

This study is expected to raise the attention to the consideration of serum iron status at the diagnosis and as a prognostic marker of breast cancer. Whether high or low levels were encountered, a balance should be taken for the best outcome of the patient.

\section{Materials and Methods}

This is a case-control study that measured serum iron, TIBC and transferrin saturation percent in newly diagnosed breast cancer at Khartoum Oncology Hospital $(\mathrm{KOH})$ and apparently healthy Sudanese females in Khartoum State, in the period from February to August 2015.

Females confirmed histopathologically to have breast cancer within one month of the date of histopathology report regardless of the menopausal status, with no other chronic condition or not under treatment with iron supplements which affect the result 
were included in this study. Breast cancer patients diagnosed histologically more than one month, breast cancer patients under- radiation or hormonal or chemotherapy and patients receiving therapeutic iron were excluded from this study.

The control group included apparently healthy females matched to patients in age group and parity. Women not known to have any cancer, chronic illness, anaemia or taking iron supplements were selected.

The samples size was set by using the formula:

$$
n=\frac{N}{N+\left(d^{2}\right)}
$$

$n=$ sample size

$N=$ total number of females newly diagnosed with breast cancer per year

$d=$ degree of precision (0.05) [6].

According to the formula, sample size is 100 samples and was set to be 120

(50 as cases and 70 as controls).

Cases were selected using simple random sampling technique. The control group was selected using stratified sampling technique from the 41 Primary Health Centers (PHCS) distributed among the seven localities of Khartoum State. Data concerning population size and PHCs were collected from the website of Ministry of Health Khartoum State.

Data were collected through an interview using a questionnaire which contains the following variables: age, marital status, parity, menopausal status, chronic illness, the presence of cancer, treatment, use of iron supplements. The date, type of breast cancer, and histopathological grade were reported from the patients' clinical records.

Five $\mathrm{ml}$ of the Blood were collected from the superficial vein in the antecubital fossa from the study population under the sterile condition and collected in a plain container, centrifuged to get serum and kept at -20 till the samples were analysed.

\subsection{The Method of Serum Iron Measurement}

Estimation of serum iron was performed using a manual method (IRON-FERROZINE) [7] based on the fact that transferrin-bound ferric ions in the sample are released by guanidinium and reduced to ferrous by means of an ascorbic acid. Ferrous ions react with ferrozine forming a coloured complex that can be measured by a spectrophotometer (CECIL instrument, Cambridge England 1000 series) [7].

The procedure was briefly as follows:

Three test tubes were labelled (sample-sample blank-standard). $1.0 \mathrm{ml}$ from working reagent was placed in a tube labelled with the sample and the standard. $1.0 \mathrm{ml}$ from reagent A was placed in the tube labelled with sample blank. $200 \mu \mathrm{L}$ from the sample 
was added to the tube labelled with sample and sample blank. $200 \mu \mathrm{L}$ from standard was added to the tube labelled with the standard. All tubes were mixed thoroughly and let stand for 5 minutes at room temperature. Absorbance $(A)$ for all tubes was read at $560 \mathrm{~nm}$ against distilled water.

Serum iron concentration was calculated using the following general formula:

Concentration of serum iron in sample $=$

$\frac{\text { Absorbance of sample }- \text { Absorbance of sample blank }}{A \text { of standard }} \times$ Concentration of standard

The Reference value in women is 50-170 $\mu \mathrm{g} / \mathrm{dL}$ [7].

\subsection{The Method of Total Iron Binding Capacity Measurement}

Estimation of total iron binding capacity (TIBC) was performed by using a manual method (IRON-FERROZINE) with the following principle:

Excess of $\mathrm{Fe}^{+3}$ is added to the sample to saturate serum transferrin. Uncomplexed $\mathrm{Fe}^{+3}$ is precipitated with magnesium hydroxide carbonate and the iron bonded to protein in the supernatant is then spectrophotometrically measured [7].

The procedure was briefly as follows:

$1.0 \mathrm{ml}$ from reagent A was placed in a clean dry test tube. $0.5 \mathrm{ml}$ from the sample was added. The test tube was mixed thoroughly and let stand for 5-30 minutes at room temperature. One spoonful of reagent B was added. The test tube was mixed thoroughly and let stand for 30-60 minutes at room temperature. The test tube was centrifuged at a minimum 3000 round per minute for 10 minutes. The supernatant was carefully collected [7]. The serum iron concentration in the supernatant was measured using the kit of iron from Biosystems Company, Barcelona (Spain).

Total iron binding capacity $($ TIBC $)=$

Serum iron concentration in supernatant $\times 3$

3 = dilution factor.

The reference value is $250-425 \mu \mathrm{g} / \mathrm{Dl}$ in adults [7].

\subsection{Calculation of Transferrin Saturation Percent}

$$
\begin{aligned}
& \text { Trans ferrin saturation percent }= \\
& \frac{\text { serum iron concentration }}{T I B C} \times 100
\end{aligned}
$$

The reference value in women is $15-50 \%$ [7] 


\subsection{Data Analysis}

Data were computed and analysed using Statistical Package for Social Science (IBM SPSS version 22.0) computer software. Pearson Chi-squire, Student $t$-test and Oneway ANOVA were used. P. value at 0.05 was considered statistically significant.

\section{Results}

The study was conducted on 120 samples, 50 breast cancer cases and 70 non-cancer controls. The mean age of the studied case group was $47 y e a r s$ and 42 years in the control group with the most common age group 45-54 years and 35-44 years, respectively, while the mean of parity number was 4 in both groups. There were $49.0(98.0 \%)$ married females and $1.0(2.0 \%)$ was single in the case group, $43.0(61.4 \%)$ married, 11.0 $(15.7 \%)$ single, 8.0(11.4\%) divorced and 8.0(11.4\%) widow in the control group.

The mean of serum iron in the study group is shown in Table1.

The mean of serum iron in invasive ductal carcinoma $247.76(\mu \mathrm{g} / \mathrm{dL}), 188.00(\mu \mathrm{g} / \mathrm{dL})$ in stromal sarcoma and $254.00(\mu \mathrm{g} / \mathrm{dL})$ in non-invasive ductal carcinoma.

Table (2) showed the mean of serum iron, mean of TIBC and mean of transferrin saturation percent in different histopathological grades of breast carcinoma according to Modified Bloom Richardson's grading system.

Table (3) stated the mean of serum iron, mean of TIBC and mean of transferring saturation percent in menopausal and non-menopausal breast cancer patients.

\section{Discussion}

It is known that iron is present throughout the body. Most physiologically active, but some are stored for future use. The intracellular space of the liver and bone marrow contains the majority of the stored iron. Iron is stored for the most part in the form of ferritin, which is composed of iron and a protein called apoferritin, when apoferritin is unavailable, iron is stored as hemosiderin [8].

Iron is an essential metal vital for living cells and may be the main culprit in tumour immunosuppression. It plays a role in the different mechanisms and functions of tumorigenesis [9]. It is required by a large number of heme and non-heme enzymes and proteins, which have essential functions in oxygen transport and oxidative phosphorylation [10].

Preclinical and clinical models proved that iron metabolism is deregulated in breast cancer [11]. Iron is a cofactor for ribonucleotide reductase, an enzyme that converts ribonucleotides to deoxyribonucleotides for the synthesis and repair of DNA. Thus it is 


\begin{tabular}{ll|l|l|l|l} 
Parameters & status & N & Mean & $\begin{array}{l}\text { SD. } \\
\text { Deviation }\end{array}$ & P. value \\
$\begin{array}{l}\text { Serum iron } \\
(\mu \mathrm{g} / \mathrm{dL})\end{array}$ & Case & 50.0 & 244.30 & 151.598 & 0.000 \\
\hline TIBC* $(\mu \mathrm{g} / \mathrm{dL})$ & Control & 70.0 & 57.59 & 43.191 & \\
& Case & 50.0 & 412.98 & 177.460 & 0.838 \\
\hline $\begin{array}{l}\text { Control } \\
\text { Saturation } \\
\text { percent }(\%)\end{array}$ & 70.0 & 403.71 & 168.765 & \\
\hline & Case & 50.0 & 61.08 & 41.523 & 0.000 \\
\hline
\end{tabular}

TABLE 1: Serum iron concentration, TIBC, and transferrin saturation percent among the study population. N $=$ Number, ${ }^{*}$ TIBC $=$ Total Iron Binding Capacity.

a crucial element in DNA synthesis, and a constant supply of iron is required to maintain DNA activity [12]. Being highly proliferative, tumour cells need more iron and they usually show high intracellular iron concentration $[13,14]$. The growth of mammary adenocarcinoma cell xenografts in rats was inhibited by low iron diet [15]. Moreover, exposing the dividing tumour cells to different iron chelators inhibited proliferation and lead to cell cycle arrest in in vitro as well as in vivo models [16-18].

The status of systemic iron is normally regulated by Hepcidin, which is a liver peptide hormone. It blocks iron release from enterocytes into plasma [19]. In cultured breast cancer cells, the expression of ferroportin proved to be negatively regulated by hepcidin through a post-transcriptional mechanism. Moreover, since the concentration of hepcidin is higher in tumour cells than in normal cells, the higher hepcidin/ferroportin ratio increases the expressionof ferritin and subsequently, raises the iron labile pool in cancer cells [20].

Though the mechanisms of miss-regulated expression of iron-related genes are not clearly known, the fundamental signalling of iron homoeostasis, the hepcidinferroportin axis was found to promote the growth of breast cancer when disordered [21]. Zhang et al found high levels of serum hepcidin in patients with breast cancer and greatly reduced concentration of tumour ferroportin in breast tumours, especially in malignant tumours, compared to adjacent tissues [19]. Further, they verified that high levels of ferroportin inhibited cell proliferation in vitro and in vivo by knocking down the expression of tumour hepcidin. So, to lock up breast cancer growth, targeting the hepcidin-ferroportin signalling pathway would signify a talented therapeutics [19].

Furthermore, high ferritin level in some solid tumours, including breast cancer, has been reported by several studies [22]. Pusatcioglu et al reported the significantly higher level of iron accumulation in colonic tissue of colorectal cancer patients compared to controls [21]. Moreover, an independent relationship between the level of serum ferritin and hepatocellular carcinoma was found in patients with chronic liver 


\begin{tabular}{|c|c|c|c|c|c|}
\hline parameter & $\begin{array}{l}\text { Histopathological } \\
\text { grade* }\end{array}$ & $\mathrm{N}$ & mean & SD deviation & P. value \\
\hline \multirow{3}{*}{$\begin{array}{l}\text { Serum iron } \\
(\mu \mathrm{g} / \mathrm{dL})\end{array}$} & 1 & 3.0 & 248.67 & 147.873 & 0.883 \\
\hline & ॥ & 31.0 & 252.06 & 168.055 & \\
\hline & III & 16.0 & 228.44 & 123.601 & \\
\hline \multirow{3}{*}{$\begin{array}{l}\text { TIBC } \\
(\mu \mathrm{g} / \mathrm{dL})\end{array}$} & 1 & 3.0 & 343.00 & 104.446 & 0.019 \\
\hline & II & 31.0 & 467.10 & 185.205 & \\
\hline & III & 16.0 & 321.25 & 129.657 & \\
\hline \multirow{3}{*}{$\begin{array}{l}\text { Transferrin } \\
\text { Saturation } \\
\text { percent } \\
(\%)\end{array}$} & I & 3.0 & 71.00 & 28.844 & 0.531 \\
\hline & II & 31.0 & 55.85 & 37.209 & \\
\hline & III & 16.0 & 69.38 & 51.015 & \\
\hline
\end{tabular}

TABLE 2: Serum iron concentration, TIBC and transferrin saturation percent in different histopathological grades of breast cancer among respondents. $\mathrm{N}=$ Number, $\mathrm{TIBC}=$ Total Iron Binding Capacity, ${ }^{*}$ Modified Bloom Richardson's grading system.

\begin{tabular}{|c|c|c|c|c|c|}
\hline parameters & $\begin{array}{l}\text { Menopausal } \\
\text { status }\end{array}$ & $\mathrm{N}$ & Mean & SD deviation & P. value \\
\hline \multirow{2}{*}{$\begin{array}{l}\text { Serum iron } \\
(\mu \mathrm{g} / \mathrm{dL})\end{array}$} & Yes & 23.0 & 423.0 & 150.40 & 0.691 \\
\hline & NO & 27.0 & 403.0 & 200.03 & \\
\hline \multirow[t]{2}{*}{ TIBC $(\mu \mathrm{g} / \mathrm{dL})$} & Yes & 23.0 & 272.0 & 178.48 & 0.224 \\
\hline & NO & 27.0 & 220.0 & 122.70 & \\
\hline \multirow{2}{*}{$\begin{array}{l}\text { Transferrin } \\
\text { Saturation } \\
\text { percent (\%) }\end{array}$} & Yes & 23.0 & 62.0 & 34.88 & 0.691 \\
\hline & NO & 27.0 & 60.0 & 47.09 & \\
\hline
\end{tabular}

TABLE 3: Correlation of menopausal status and concentration of serum iron, TIBC and transferrin saturation percent in breast cancer patients. $\mathrm{N}=$ Number, TIBC = Total Iron Binding Capacity.

disease due to viruses [23]. A relative risk (RR) of 1.03; $95 \% \mathrm{Cl}, 0.97-1.09$ for breast cancer for an increase of $1 \mathrm{mg} /$ day of heme iron consumption was reported. The greater consumption of heme iron, but not serum ferritin has shown a tendency toward a positive association with cancer risk [24].

On the other hand, there are reliable publications linking the mutations of $\mathrm{C}_{2} 82 \mathrm{Y}$ and $\mathrm{H}_{63} \mathrm{D}$ in the High Iron Fe (HFE) which is encoded by the hemochromatosis gene that causes iron overload (heterozygous mutations) and hereditary hemochromatosis of type I (homozygous mutations) to the risk of developing breast cancer (Odds ratios ranging between 2.05 and 4.4) $[25,26]$. However, a study on pre-menopausal women did not demonstrate any association between HFE single nucleotide polymorphysm SNPs and risk of breast cancer [27]. 
During the early steps of carcinogenesis the gene encoding human ferritin (FTH) is found to be up-regulated [28]. Interestingly, the ectopic expression of microRNA $200 \mathrm{~b}$ that negatively regulates FTH in breast cancer cells has shown a better response to doxorubicin in vitro [29]. The iron labile the pool is increased through inhibition of ferroportin expression and stimulation of ferritin expression through iron regulatory protein 2 (IRP2), which is overexpressed in breast cancer, hence playing an early role in cancer-related iron overload [30].

In spite of its importance for cell respiration, iron can cause oxidative stress and DNA damage [11]. $\mathrm{Fe}^{2+}$ catalyses the production of very active hydroxyl radicals, through the Fenton and Haber-Weiss reactions, that can form DNA adducts and initiate carcinogenesis [11]. Furthermore, breast carcinogenesis is promoted by stimulating tumour growth through activation of oestrogen receptors by oestrogens and also by the production of genotoxic metabolites of estradiol. DNA adducts can further be formed by catechols and their quinoline derivatives and they can favour the occurrence of mutations. The growth of breast tumours is stimulated by oxidised derivatives of oestrogens [31]. The oxidative stress produced by iron could favour the production of these genotoxic metabolites [11].

Physiologically, hepcidin expression is negatively regulated by increased erythropoiesis [32] or hypoxia and contrariwise, it is inspired by the high level of circulating iron and by inflammation. The expression of hepcidin is induced by lipopolysaccharides (LPS) and interleukin 6 (IL-6) during inflammation, which activates hepcidin synthesis through the signal transducer and activator of transcription 3 (STAT3) pathway [32].

Thus, iron overload is incriminated in carcinogenesis via different mechanisms including the assembly of free radicals, development of oxidative stress, the interaction with other carcinogens and genetic mutations in addition to immunomodulation [11].

In this study 120 females, 50 as cases with breast cancer and 70 as non-breast cancer controls were involved; for all those women serum iron, TIBC and transferrin saturation percent were measured or calculated. It revealed a statistically significant increase in the mean of serum iron and decrease in transferrin saturation percent in women with breast cancer while no significant variation in the mean of TIBC between case and control groups. The finding of Pavithra et al in their study is similar to this study in serum iron level; they found significantly high levels of serum iron in 54 female patients with breast cancer when compared to 54 female controls [33].

In the study conducted by Dhankha et al, it was found that the serum iron level, TIBC and transferrin saturation percent were significantly elevated in sixty breast cancer patients as compared to thirty healthy controls [34]. Though agree with results concerning serum iron but disagree in the level of TIBC and transferrin saturation percent in the current study. This could be attributed to the methods used. 
Transferrin (TF), a bi-lobed glycoprotein is the chief iron transport protein in the mammalian blood [35]. There is no significant variation in the mean of serum iron and transferrin saturation percent according to the type of breast cancer and histopathological grade in this study, but there is a significant increase in the mean of TIBC in females with grade II. That is disagreeing with Dhankhar et al study in which they reported that patients with advanced disease showed greater values as compared to an early stage, as patients in the current study were in the early stage of the disease because all patients were taken in this study within one month of histopathology report. Nevertheless, there is an agreement regarding TIBC [34].

Interestingly, Dhankhar et al analysed iron, ferritin and TIBC in thirty patients with early stage, thirty with advanced stage breast carcinoma before and after treatment and the results were related to thirty healthy controls. Breast cancer patients showed significantly higher levels of all the three parameters as related to healthy controls and patients with advanced disease showed greater values as when matched to early stage disease. Additionally, there is a decrease in these levels following treatment significantly in patients with complete response [34]. Therefore, serum analyses of iron, ferritin and TIBC may be of prognostic help in assessing the severity of breast cancer.

Furthermore, a cohort study done by Wen et al in 309,443 adults in Taiwan in women who had no history of cancer had serum iron levels tested at the time of recruitment. The authors associated the firstly measured iron levels with subsequent cancer risk by connecting individuals with the National Cancer Registry and National Death File. The relationship between serum iron and cancer risk was a J-shaped one, with higher cancer risk at both ends, either at lower than $60 \mathrm{mg} / \mathrm{dL}$ or higher than $120 \mathrm{mg} / \mathrm{dL}$ [36]. High serum iron could be either a common disorder or/and a biochemical marker of increased risk for breast cancer [36].

On the other hand, there is no significant variation in the mean of transferrin saturation percent, TIBC and serum iron in menopausal and non- menopausal female in this study. Nevertheless, another study reported that serum iron is a weak risk factor in menopausal women (Hazard ratio of standardized SI 1.09 (95\% Cl 1.02-1.015) [37]. High levels of stored iron may act as a risk factor for mortality due to cancer in postmenopausal women and may be attributed by a buildup of stored iron among women after menopause [37].

The limitation of this study includes small sample size besides the use of the manual methods. More studies should be undertaken with adequate sample size and more advanced method for measurement of serum iron and TIBC must be used. 


\section{Conclusion}

In spite of its limitations, this study concluded that there is a statistically significant difference in serum iron (increased) and transferrin saturation percent (decreased) between Sudanese females newly diagnosed with breast cancer and apparently healthy females. While there is no significant difference in TIBC between Sudanese females newly diagnosed with breast cancer and apparently healthy females. Serum iron, TIBC and transferrin saturation percent did not vary in regard to the type of breast cancer and menopausal status. TIBC but not serum iron and transferrin saturation percent vary significantly according to histopathological grade. The results of this study affirm the previous studies that serum iron and transferrin saturation percent may be helpful as biochemical risk markers for breast cancer and that TIBC may act as a predictor of disease grade.

\section{Acknowledgements}

We would like to thank the staff of the Research Laboratory at Sudan University of Science and Technology for their availability at any time and their help in doing this work very easily.

\section{Ethical Consideration}

Informed consent was written and signed by each participant following explanation of the study and sample collection procedure. The participants' information was kept confidential. Ethical approval was obtained from the Ministry of Health, Khartoum State. A permission of study conduction was taken from the Head Administrative of $\mathrm{KOH}$.

\section{Competing Interests}

Authors declare that they have no competing interests.

\section{Availability of Data and Material}

Data are available upon request. 


\section{Funding}

None.

\section{Abbreviations and Symbols}

$\mathrm{KOH}:$ Khartoum Oncology Hospital

PHCs: Primary Health Centers

TIBC=Total Iron Binding Capacity

\section{Author Contributions}

Both authors participated in:

1. The study concept and design, analysis, and interpretation of data.

2. Drafting the article, Revising it critically for important intellectual content.

3. Final approval of the version to be published.

4. Agreement to be accountable for accuracy and integrity of all aspects of the work.

\section{References}

[1] R. L. Siegel, K. D. Miller, S. A. Fedewa et al., "Colorectal cancer statistics, 2017," CA: A Cancer Journal for Clinicians, vol. 67, no. 3, pp. 177-193, 2017.

[2] I. E. Saeed, H.-Y. Weng, K. H. Mohamed, and S. I. Mohammed, "Cancer incidence in Khartoum, Sudan: First results from the Cancer Registry, 2009-2010," Cancer Medicine, vol. 3, no. 4, pp. 1075-1084, 2014.

[3] BF. Rodak, GA. Fritsma, and E. Keohane, Hematology, clinical principles and applications, ISBN 0323292690, Elsevier Health Sciences, 2013.

[4] D. Ćujić, I. Stefanoska, and S. Golubović, "Serum Ferritin in Healthy Women and Breast Cancer Patients," Journal of Medical Biochemistry, vol. 30, no. 1, 2011.

[5] J. G. Liehr and J. Shawn Jones, "Role of iron in estrogen-induced cancer," Current Medicinal Chemistry, vol. 8, no. 7, pp. 839-849, 2001.

[6] T. Yamane, Statistics, an introductory analysis-3, http://www.worldcat.org/title/ statistics-an-introductory-analysis/oclc/39121222.

[7] Barbara J. B., Dacie and Lewis Practical Haematology. 12th ed. China: Elsevier; 2017. ISBN 978-0-7020-6696-2. 
[8] E. A. Stiene-Martin, C. A. Lotspeich-Steininger, and J. A. Koepke, Clinical hematology: principles, procedures, correlations, Lippincott Williams \& Wilkins, 1998.

[9] R. L. Elliott and J. F. Head, "Cancer: Tumor Iron Metabolism, Mitochondrial Dysfunction and Tumor Immunosuppression; "A Tight Partnership-Was Warburg Correct?"," Journal of Cancer Therapy, vol. 03, no. 04, pp. 278-311, 2012.

[10] R. L. Elliott, M. C. Elliott, F. Wang, and J. F. Head, "Breast Carcinoma and the Role of Iron Metabolism," Annals of the New York Academy of Sciences, vol. 698, no. 1, pp. 159-166, 1993.

[11] P.-J. Lamy, A. Durigova, and W. Jacot, "Iron homeostasis and anemia markers in early breast cancer iron and breast cancer.," Clinica Chimica Acto, vol. 434, Pp. 34-40, 2014.

[12] O. Marques, B. M. da Silva, G. Porto, and C. Lopes, "Iron homeostasis in breast cancer," Cancer Letters, vol. 347, no. 1, pp. 1-14, 2014.

[13] D. R. Richardson, "The iron metabolism of neoplastic cells: Alterations that facilitate proliferation?" Critical Reviews in Oncology/Hematology, vol. 42, no. 1, pp. 65-78, 2002.

[14] M. W. Hentze, M. U. Muckenthaler, B. Galy, and C. Camaschella, "Two to tango: regulation of mammalian iron metabolism," Cell, vol. 142, no. 1, pp. 24-38, 2010.

[15] F. Wang, R. L. Elliott, and J. F. Head, "Inhibitory effect of deferoxamine mesylate and low iron diet on the 13762NF rat mammary adenocarcinoma," Anticancer Res, Article ID 10226580, pp. 445-50, 1999.

[16] X. P. Jiang, F. Wang, D. C. Yang, R. L. Elliott, and J. F. Head, "Induction of apoptosis by iron depletion in the human breast cancer MCF-7 cell line and the $13762 \mathrm{NF}$ rat mammary adenocarcinoma in vivo," Anticancer research, vol. 22, no. 5, pp. 26852692, 2001.

[17] J. Blatt, Taylor Sr., and S. Stitely, "Mechanism of antineuroblastoma activity of deferoxamine in vitro," The Journal of laboratory and clinical medicine, vol. 112, no. 4, Article ID 2459279, pp. 433-436, 1988.

[18] E. M. Hoke, C. A. Maylock, and E. Shacter, "Desferal inhibits breast tumor growth and does not interfere with the tumoricidal activity of doxorubicin," Free radical biology medicine, vol. 39, no. 3, Article ID 15993339, Pp. 403-11, 2005.

[19] S. Zhang, Y. Chen, W. Guo et al., "Disordered hepcidin-ferroportin signaling promotes breast cancer growth," Cellular Signalling, vol. 26, no. 11, pp. 2539-2550, 2014.

[20] Z. K. Pinnix, L. D. Miller, W. Wang et al., "Ferroportin and iron regulation in breast cancer progression and prognosis," Science Translational Medicine, vol. 2, no. 43, Article ID 43ra56, 2010.

[21] C. K. Pusatcioglu, E. Nemeth, G. Fantuzzi, X. Llor, S. Freels, L. Tussing-Humphreys et al., "Systemic and tumor level iron regulation in men with colorectal cancer: a case control study. Nutrition \& Metabolism. 2014;11:21". 
[22] G. Güner, G. Kirkali (Bilgin), Ç. Yenisey, and i. Töre, "Cytosol and serum ferritin in breast carcinoma," Concer Letters, vol. 67, no. 2-3, pp. 103-112, 1992.

[23] P. S. Patil, K. M. Mohandas, S. J. Bhatia, and S. A. Mehta, "Serum ferritin and the risk of hepatocellular carcinoma in chronic liver disease of viral etiology: A case-control study," Indian Journal of Gastroenterology, vol. 33, no. 1, pp. 12-18, 2014.

[24] A. Fonseca-Nunes, P. Jakszyn, and A. Agudo, "Iron and cancer risk-a systematic review and meta-analysis of the epidemiological evidence. Cancer epidemiology, biomarkers prevention : a publication of the American Association for Cancer Research," cosponsored by the American Society of Preventive Oncology, vol. 23, no. 1, Article ID 24243555, pp. 12-31, 2014.

[25] A. Gunel-Ozcan, S. Alyilmaz-Bekmez, E. N. Guler, and D. Guc, "HFE H63D mutation frequency shows an increase in Turkish women with breast cancer," BMC Concer, vol. 6, article no. 37, 2006.

[26] T. V. Kondrashova, K. Neriishi, S. Ban et al., "Frequency of hemochromatosis gene (HFE) mutations in Russian healthy women and patients with estrogen-dependent cancers," Biochimica et Biophysica Acto - Molecular Basis of Disease, vol. 1762, no. 1, Pp. 59-65, 2006.

[27] R. E. Graff, E. Cho, S. Lindstrcom, P. Kraft, W. C. Willett, and A. H. Eliassen, "Premenopausal plasma ferritin levels, HFE polymorphisms, and risk of breast cancer in the nurses' health study II," Cancer Epidemiology Biomarkers and Prevention, vol. 23, no. 3, pp. 516-524, 2014.

[28] N. A. Higgy, A. M. Salicioni, I. H. Russo, P. L. Zhang, and J. Russo, "Differential expression of human ferritin $\mathrm{H}$ chain gene in immortal human breast epithelial MCF10F cells," Molecular Carcinogenesis, vol. 20, no. 4, pp. 332-339, 1997.

[29] S. I. Shpyleva, V. P. Tryndyak, O. Kovalchuk et al., "Role of ferritin alterations in human breast cancer cells," Breast Cancer Research and Treatment, vol. 126, no. 1, pp. 63-71, 2011.

[30] W. Wang, Z. Deng, H. Hatcher et al., "IRP2 regulates breast tumor growth," Cancer Research, vol. 74, no. 2, pp. 497-507, 2014.

[31] J. D. Yager, "Molecular Mechanisms of Estrogen Carcinogenesis," Annual Review of Pharmacology and Toxicology, vol. 36, no. 1, pp. 203-232.

[32] D. M. Wrighting and N. C. Andrews, "Interleukin-6 induces hepcidin expression through STAT3," Blood, vol. 108, no. 9, Pp. 3204-3209, 2006.

[33] V. Pavithra, T. G. Sathisha, K. Kasturi, D. Siva Mallika, S. Jeevan Amos, and S. Ragunatha, "Serum levels of metal ions in female patients with breast cancer," Journal of Clinical and Diagnostic Research, vol. 9, no. 1, Pp. BC25-BC27, 2015.

[34] R. Dhankhar, A. C, K. Dahiya, V. S. Ghalaut, A. K. Dhull, and A. Khurana, "Role of Iron Metabolism in Breast Cancer Patients," Concers Review, vol. 1, no. 2, pp. 45-51, 2014. 
[35] C. A. Finch, S. Stray, H. A. Huebers, V. Bellotti, D. A. Lipschitz, J. D. Cook et al., "Plasma Ferritin Determination as a Diagnostic Tool," Western Journal of Medicine, vol. 145, no. 5, pp. 657-63, 1986.

[36] C. P. Wen, J. H. Lee, Y. Tai et al., "High Serum Iron Is Associated with Increased Cancer Risk," Concer Research, vol. 74, no. 22, pp. 6589-6597, 2014.

[37] A. Gaur, H. Collins, W. Wulaningsih, L. Holmberg, H. Garmo, and N. Hammar, "Iron metabolism and risk of cancer in the Swedish AMORIS study," Cancer causes \& control : CCC, vol. 24, pp. 1393-1402, 2013. 